\title{
Research on the Security of Accounting Information System in the Big Data Era
}

\author{
Boris Zhenhan Hu \\ Bishop Amat Memorial High School, US \\ Email: zhenhanhu16@gmail.com
}

\begin{abstract}
Since the 21st century, information technology has made tremendous progress. Especially in recent years, the concept of big data has attracted more and more attention. Accounting information security and the construction and maintenance of accounting information systems are also facing huge opportunities and challenges. At present, in the era of big data, the importance of accounting information security and accounting work is increasing day by day. If the accounting information system is not properly analyzed, it will lead to the disclosure of financial information, and in severe cases, it will even harm the economic interests of the enterprise. This article analyzes the development of accounting information system security with the theme of strengthening information security.
\end{abstract}

Keywords: Information system, Accounting, Big data era, Security

\section{Introduction}

Big data technology can acquire, analyze and process data information in a short period of time, and then use the processed information to solve problems that cannot be solved by humans [1]. In the accounting industry, big data can be used to collect and process information resources, while ensuring the efficiency of information processing and improving the efficiency of comprehensive information utilization. The most important thing is to realize the processing of classified information and effectively promote the progress and development of various industries. With the widespread use of various software, the importance of big data in the information industry and the Internet industry has become increasingly prominent [2]. With the advent of the era of big data, the development of the accounting industry has shown a different state. As accounting professionals, we should analyze and process these resources. When you need information, you can get it quickly. Through the processing of relevant software data and information, the resource sharing of various industries is realized, and the overall utilization efficiency of resources is effectively improved.

\section{The characteristics of accounting information system security in the era of big data}

With the birth and rapid development of information technology, today's society is gradually changing from an industrial society to an information society [3]. The era of knowledge economy and information technology has come, and the accounting environment has undergone great changes. The emergence of the network economy has put forward new requirements for the traditional accounting industry, and has had an unprecedented strong impact on the concepts, theories and methods of traditional accounting, which requires the accounting industry to undergo changes. Financial workers must carry out a comprehensive innovation of the accounting information system to adapt to the requirements of the new economic form. The era of big data offers advanced technical ways to accounting information systems, and it also makes information security more important in the era of big data. Whether external information needs or internal information users, all aspects of society have higher requirements for the collection, processing and transmission of information. With the improvement of the openness and liquidity of information, these important accounting information data will flow accordingly, and it is easy to be used for illegal purposes by some people or companies with ulterior motives. Therefore, it is very necessary to improve the security of the accounting information system, whether for individuals, enterprises or countries. 


\section{Problems in the security of accounting information systems in the era of big data}

\subsection{Theft or loss of important information}

The accounting information system adopts network technology, which makes the system have the characteristics of sharing and openness, which provides convenience for users. However, while sharing and openness, it also allows external criminals to use it [4]. They use the limitations of the Internet to steal and destroy financial information. On the one hand, there is no encrypted traffic on the Internet to realize users' sharing and open systems, which leads to potential risks and problems in the process of changing personal information. There are many ways to intercept and hijack. Even on the Internet, some people provide methods for free, which has led to the rampant spread of system damage methods on the Internet. More and more people are trying to attack the system, which poses a great challenge to the security of the system. Attacks on key information systems take advantage of the characteristics of an open network system. The open and shared nature of the network system also allows many business users to access the financial information of the entire enterprise through authorized permissions, and increases the chance of financial information theft.

Professionals also use their positions to commit fraud. According to domestic and foreign statistics, although the number of errors and accounting frauds in the use of network accounting information systems is decreasing, the losses caused by errors and frauds are more serious [5]. First of all, the accounting information system will leave traces in the process of use, and these traces will become tools used by hackers. There are also some operators who can take advantage of their location to obtain illegal benefits. Secondly, since the network accounting information system is not restricted, the management may have fraud in internal control without the constraints of internal control.

\subsection{Accounting information systems are vulnerable to hackers and viruses}

There are many ways of hacking, most of which exploit system and computer vulnerabilities. The existence of these vulnerabilities gives hackers the opportunity to use illegal means to send extra data to the target system, which causes the system to stop service and cause a serious system crash. Among hacker attacks, Trojan horses are a very common and more efficient means of attack. The purpose of the attack is achieved through the password of the system administrator. This type of attack is usually aimed at the computer system, and the result of the attack will cause the computer system to run slowly or even crash.

Computer virus is a major risk faced by computer systems. Computer viruses will spread in a short period of time and cannot be controlled. The replication characteristics of computer viruses can be extremely destructive. The well-known computer virus network worm can spread within the Internet within a short period of time and destroy the network environment.

\subsection{Lack of professional and technical personnel}

In the network accounting information system, relevant personnel must have professional knowledge of accounting and information technology. In general enterprises, accountants should undergo professional information technology training before they start their careers. However, in the actual training process, there is still a certain gap between information technology and the actual needs of relevant personnel. With the advancement of science and technology, human society is gradually renewed, and people's lifestyles are also undergoing significant changes. There are also obvious changes in the business model of enterprises, which is reflected in the accounting work. On the one hand, many old accountants are familiar with accounting business. But they are limited to the computerization of computers and cannot grasp the operation of the network accounting information system. Although young people are more accustomed to the rhythm of the Internet age, they are relatively young and inexperienced in accounting. In addition, the development of early accounting software in my country mainly relied on computer talents. They know very little about meetings, auditing and financial management. It was not until later that computers and accounting became forces for joint development. In this case, accountants do not understand the accounting software developed in the later stage, so they cannot deal with any problems that arise in the course of use, and cannot meet actual needs. Although there are some colleges and universities in our country that have opened accounting information technology courses, the number is not large, and the talents trained can not meet the needs of the whole society. 
The network environment puts forward higher requirements on people, which makes the information transmission in the network age present new characteristics. The moral quality and professional ability of accounting professionals have also been challenged tremendously. Accounting information security is one of the main sources of moral hazard faced by accounting practitioners. Corporate accounting practitioners must abide by professional standards and disclose relevant information to relevant global organizations. This phenomenon requires financial personnel to have a very deep understanding of China's relevant laws and regulations and industry policies and norms. Only in this way can they truly improve their abilities and effectively deal with risks. This is a big challenge for accounting practitioners.

\subsection{Lack of effective supervision}

In the era of big data, many business models have changed. With the development of the Internet, its unified technical standards have become the support of cloud computing technology. The era of big data has also realized the unification of technology. However, with the development of science and technology, the dissemination of information is gradually no longer under control, and the technical standards of big data have also formed various trends, making the application of technology chaotic. Therefore, formulating relevant standards for production safety accounting is an effective way to solve the problem of technology promotion. Special technical standards are mentioned in related reports. The development of the accounting industry needs to develop in accordance with these technical standards, so as to achieve the development of standardization. Information security is essentially the most important part of accounting information system work. Once information security issues arise, accounting will be severely affected. Therefore, we must attach importance to the standardized development of accounting security and information technology. If there is no standardized standard, information security will be threatened, or important data will be illegally occupied. Due to the lack of corresponding policy and regulatory support, the situation facing accounting information security is becoming increasingly severe.

\section{Countermeasures to improve the security of accounting information systems in the era of big data}

\subsection{Reasonable allocation of equipment resources}

For accounting information systems, both hardware and software are important components, so the security of the hardware system is also worthy of our attention. First of all, when buying computer hardware, we need to understand the large and small brands, models, and the reputation of the manufacturer, and carefully check whether there are problems with the hardware, and then continue to debug and run. Then put it in the actual use of the enterprise to ensure that it plays a better role. Secondly, we need to prevent the hidden dangers of the hardware system in the process of accounting information system application. Due to the unpredictability of natural disasters, when dealing with these risks, a more complete prevention system should be constructed from the perspective of prevention. For example, the environment where the computer is placed should be kept relatively dry and ventilated to avoid floods and fires.

There are other factors that affect safety such as magnetic fields. This is a factor that people often overlook, and it has a great impact on computers and accounting information systems. Special attention should also be paid to anti-magnetic, and a corresponding system should be established to avoid contact between the computer and nearby magnetic materials. Political environment factors such as earthquakes, typhoons, threats, etc. also need to attract people's attention. In order to deal with a particular threat, we need to establish a more complete data backup system to ensure that critical data can be effectively protected. By setting up alarms and purchasing counters, the possibility of theft of computer equipment, etc., is reduced.

\subsection{Strengthen the security prevention capabilities of the accounting information system}

Problems that stand out during the normal operation of the accounting information system will affect the normal functions and the role of the accounting information system. Therefore, when purchasing and installing, you need to operate before debugging. In daily use, it is necessary to pay attention to and record the abnormal conditions of the running software at any time, install patches in time for modification, and regularly scan and analyze the software system to solve software vulnerabilities. Antivirus software is usually used to kill viruses, and network anti-virus software is used to prevent network viruses. Anti-virus software is one of the most effective means to prevent and control computer viruses, 
but no anti-virus software can stop all computer viruses.

\section{Conclusion}

This research shows that we need to choose anti-virus software at any time and update the anti-virus software at any time to effectively protect the security of the computer system. Enterprise network security and campus environment network security can be guaranteed through anti-virus software. The study found that the network virus prevention and control system can achieve a certain network virus prevention and control effect through the centralized security management password setting of the remote local area network. It can use advanced distribution technology, use local available resources and local anti-virus engine to kill all viruses on local nodes comprehensively, timely and efficiently. At the same time, it can protect users' privacy, reduce the burden of network transmission, and avoid congestion caused by a large number of files being transferred.

\section{References}

[1] Li Wei. Analysis of the security of accounting information systems in the era of big data[J]. Computer Products and Circulation, 2018(07): 94.

[2] Qi Shaobo, Teng Haoyu. Research on the Security of Accounting Information System in the Big Data Era [J]. Economic and Trade Practice, 2017(10): 83-84.

[3] Tang Changsheng. Research on the improvement of accounting informatization in the era of big data [J]. Journal of Huainan Normal University, 2014, 16(02): 12-15.

[4] Kwarteng A, Aveh F. Empirical examination of organizational culture on accounting information system and corporate performance: Evidence from a developing country perspective[J]. Meditari Accountancy Research, 2018.

[5] Harini AS, Kurniawan A, Umiyati I. The influence of accounting information system implementation and internal control effectiveness on the performance of employees (Case study on micro, small, medium enterprises subang regency)[J]. Journal of Accounting for Sustainable Society, 2019, 1(01): 88-88. 